\title{
A Case History of Internal Ophthalmomyiasis, a Rare and Devastating Disease
}

\author{
Shams Mohammed Noman, Murtuza Nuruddin \\ Eye Infirmary and Training Complex, Chittagong, Bangladesh \\ Email address: \\ drshams_noman@yahoo.com (S. M. Noman)

\section{To cite this article:} \\ Shams Mohammed Noman, Murtuza Nuruddin. A Case History of Internal Ophthalmomyiasis, a Rare and Devastating Disease. \\ International Journal of Ophthalmology \& Visual Science. Vol. 6, No. 3, 2021, pp. 154-157. doi: 10.11648/j.ijovs.20210603.11
}

Received: May 7, 2021; Accepted: June 2, 2021; Published: July 15, 2021

\begin{abstract}
To report a rare case of unilateral internal ophthalmomyiasis with complete visual loss. Method: An otherwise healthy 12 years old boy presented with redness and painful rapid loss of vision in his right eye for the past 12 days. There was no history of associated trauma. On examination, there was no perception of light in his right eye and normal vision in left eye. There was severe anterior and posterior segment inflammation which prevented the view of fundus. B-scan of the right eye showed diffuse choroidal and optic nerve thickening. Routine blood count and X-ray chest did not reveal any significant findings. In the midst of uncertainity regarding diagnosis and to relieve the patient from severe pain, enucleation of right eye was performed and histopathological examination of the specimen was done to confirm the diagnosis. Result: Histopathology report showed gross irregular inflammatory thickening of the choroid with severe granulomatous inflammation. There was an infective agent in the choroid having an outer cuticle and an irregular hyaline branching innner tube. These features were suggestive of ophthalmomyiasis of the choroid. Conclusion: Although rare, ophthalmomyiasis should be considered in the differential diagnosis of panuveitis. Early recognition of this condition, when tumour and other conditions are suspected, would avoid invasive surgical procedures, such as enucleation.
\end{abstract}

Keywords: Ophthalmomyiasis, Maggot, Larvae

\section{Introduction}

The infestation of living vertebrate animal tissues by fly larvae (maggots) is known as myiasis [1]. Ophthalmomyiasis (Ophthalmic myiasis) is the infestation of the human eye, by the maggot of certain flies from the order of diptera.

Numerous different causative agents may be found, e.g. Cochliomyia macellaria, Oestrusbovis, Gastrophilus species, Hypodermaspecies.

The most common reported organism in the literature is Oestrusbovis, a boat fly highly prevalent in sheep herdening \& farming.

Cattle, sheep, deer and rodents are the host animal. By penetration through skin, orbit or nasal cavities, human infestation occurs. Eggs \& larvae are transported to the eye surface by vectors such as ticks, mosquito's \& also by patient's hands.

Less than $5 \%$ of human myiasis causes involvement of the eye [2]. Classification of ophthalmomyiasis is based on the portion of the eye and ocular adnexa affected. External myiasis occurs in the lid \& conjunctiva.. Larvae within the globe is called internal myiasis. Although rare, orbital myiasis may also take place. Because of lower mechanical resistance of sclera to maggot's penetration, ophthalmomyasis interna is more frequent in children.

Maggots enter or exit the eye through the sclera, blood stream or optic nerve [3].

The larva destroys the tissues with toxins \& produces protein. Proteolytic bacteria carried by maggots destroy these proteins. Enzymatic digestion, in turn provides suitable proteins for the maggot.

Myiasis of the eye lid has been reported from Cutebra larva [4] \& D. hominis causing puncture of the skin \& extrude ova beneath the surface or deposits their eggs on open wounds resulting furuncular, boil like lesions.

\section{Case Presentation}

Mr. Md. Faisal Age 12 yrs. Begumgonj, Noakhali came to CEITC with the complaints of redness and loss of vision in 
$\mathrm{R} / \mathrm{E}$ for 8 days. He hadno history of trauma.

On examination there was no perception of light in his right eye and 6/6 vision in his left eye.Right eye examination also revealed oedematous lid., Congested conjunctiva in a ciliary pattern, Hazy and oedematous cornea. Severe inflammation with organised fibrin in the anterior chamber. Pupil was irregular with posterior synechia. Lens was cataractous Posterior segment was not visible. No abnormality was detected in his left eye.

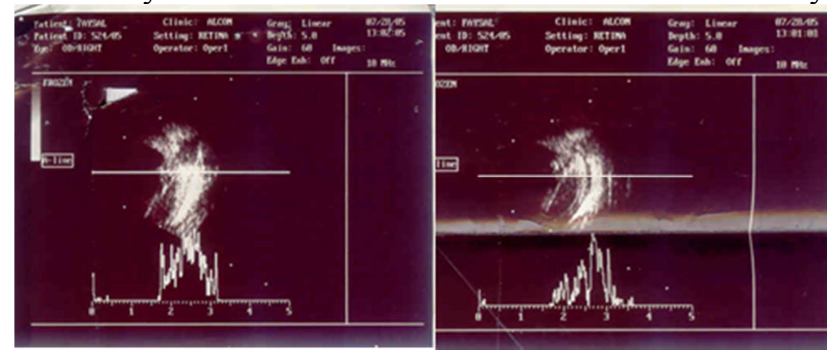

Figure 1. B scan of the affected eye.

B-scan showed diffuse choroidal and optic nerve thickening The provisional diagnosis was right sided choroidal growth with pan uveitis. He was admitted and treated conservatively. His blood picture, biochemical analysis and urine analysis was normal. Within this time he developed continuous severe pain in his right eye.Enucleation of right eye was done as indication of painful blind eye and the globe was sent for histopathological examination.

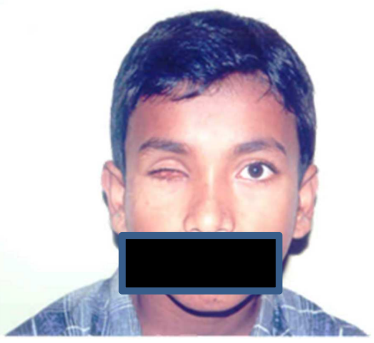

Figure 2. Anophthalmic socket.

Rt. enucleation done and the whole globe has sent to department of histopathology of Sheffield teaching hospitals of United Kingdom.

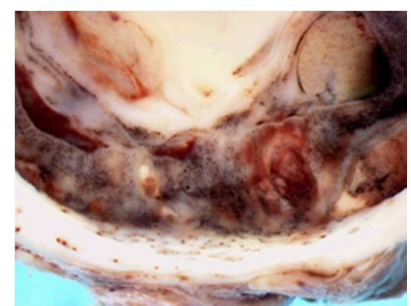

Figure 3. Cross section of the specimen.

Macroscopic image of cut surface of eye. This shows gross irregular thickening of the choroid.

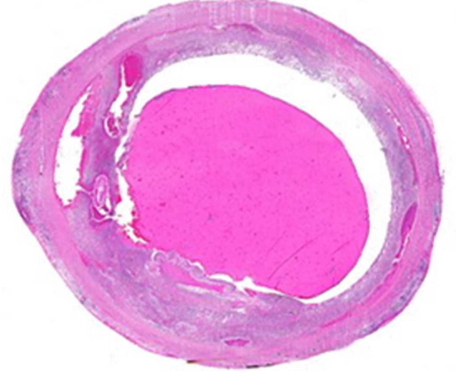

Figure 4. Cross section HE stein.

Low power haematoxylin and eosin $(\mathrm{H}$ and $\mathrm{E})$ stained image of the eyeball. There is a central eosinophilic exudates and inflammatory thickening of the choroids.

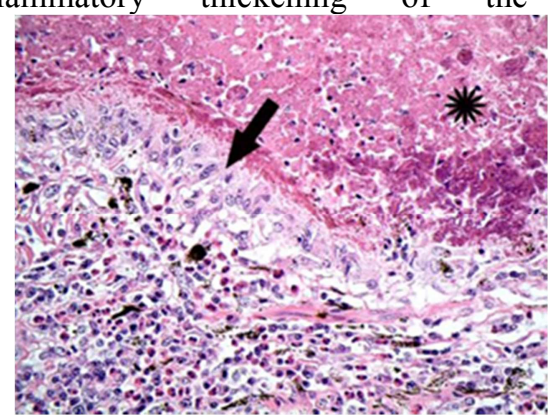

Figure 5. Histopathology slide.

Higher power $\mathrm{H}$ and $\mathrm{E}$ of the choroid shows a necrotic tract (asterisk), cuffed by granulomatous inflammation (arrow)

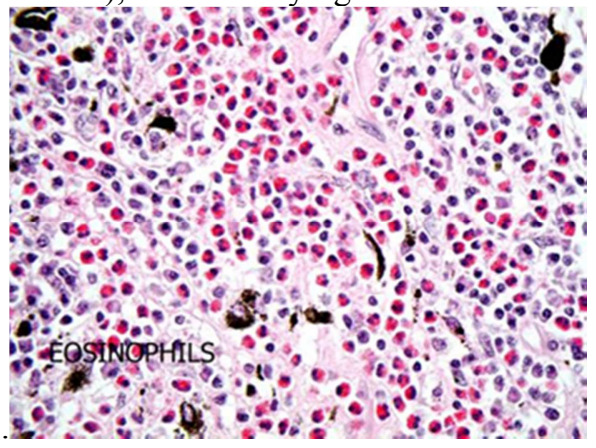

Figure 6. Histopathology.

$\mathrm{H}$ and E-The granulomatous inflammation is in turn cuffed by a dense eosinophilic inflammatory response.

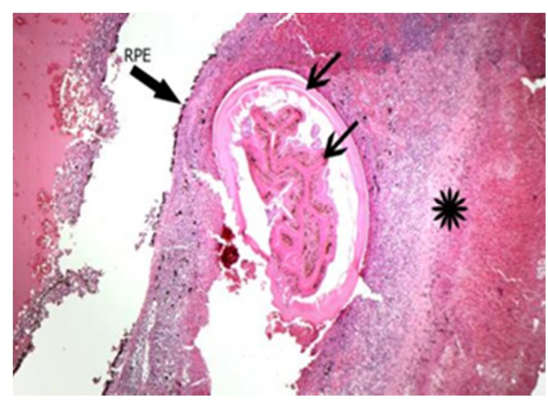

Figure 7. Histopath of choroid.

Low power $\mathrm{H}$ and $\mathrm{E}$ shows an infective agent in the choroid (arrowed). $\mathrm{PE}=$ retinal pigment epithelium. 


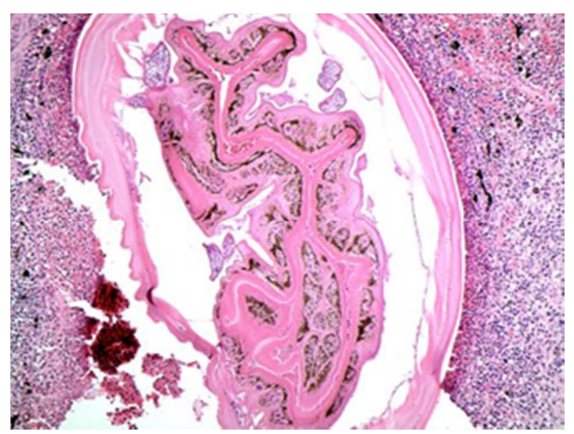

Figure 8. Histopath.

Higher power $\mathrm{H}$ and $\mathrm{E}$ showing an agent with an outer cuticle and an irregular hyaline branching inner tube.

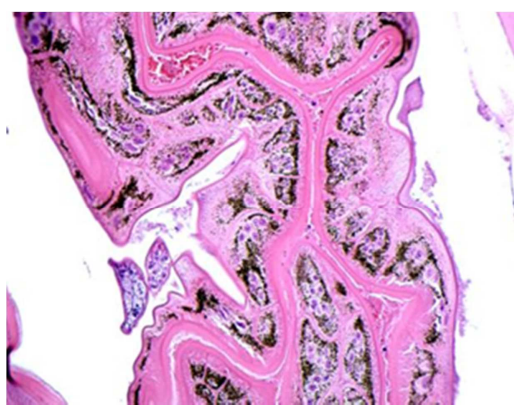

Figure 9. Magnified histopath.

Higher power $\mathrm{H}$ and $\mathrm{E}$ of theinner irregularhyaline branching tube

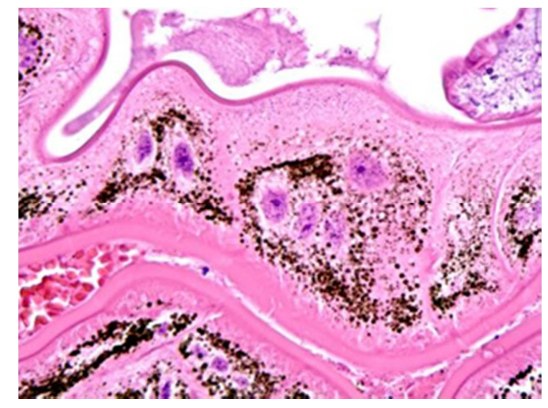

Figure 10. Magnified Histopath.

The lining cells of the inner tubeare multinucleate and contain brown pigment.

According to histopathological evidence, the patient was diagnosed as Ophthalmomyiasis of choroid (The exact genus and species of the fly is not ascertainable).

\section{Discussion}

Ophthalmic reactions to maggots have different types. The larva may remain in the eye without inducing significant inflammation. After the death of maggots it may cause mild uveitis or severe inflammation. Usually, inflammation is painless but in our case it caused painful severe panuveitis. Criss- cross pattern faint curvilinear grey white line secondary to disturbed retinal pigment epithelium is pathognomec [5]. This sub retinal track is called railroad track.
Visual loss may be the result of severe inflammation and extension of railroad tracks through the macula, retinal detachment, haemorrhage or invasion of the optic nerve. In our case visual loss may be due to severe panuveitis \& optic nerve involvement. Due to severe inflammation thorough intraocular examination \& photography was not possible.

Management depends upon the location of the maggot \& severity of inflammation.

A maggot within the vitreous cavity with mild or no inflammation could be left alone.

Steroid therapy is indicated in case of mild to moderate uveitis. [6]

Photocoagulation of subretinal maggots should be performed promptly to prevent further decrease in vision due to continued tunneling. [7, 8]

Parsplana vitrectomy can be performed.

Removal of larva from anterior chamber by aspiration or with forcep.

In case of external ophthalmomyiasis, normal forcep removal of the larvae is ideal.

Ophthalmic ointment or ethyl ether can be used to block the larvae's respiratory pore, thereby suffocating the organism to facilitate manual removal. According to data from the literature on the surgical treatment of intraocular ophthalmomyiasis, much attention has been paid to the diversity of clinical manifestations, ranging from mild symptoms such as eye redness to severe uveitis and panophtalmitis with total retinal detachment.[9] An interesting fact is that the larvae can migrate between cavities of the eye, from the anterior chamber and vitreous cavity in subchorioidal space $[10,11]$.

\section{Conclusion}

Although rare, Ohthalmomyiasis may be presented with red eye with decrease vision due to retinal involvement. Untreated cases may cause panuveitis like syndrome. Early recognition with a detailed external \& internal ophthalmic examination is necessary to save the eye with early appropriate treatment.

\section{References}

[1] Albert \& Jakobiec. Principles and practice of ophthalmology Vol-4. 3347.

[2] MC, Lee KY, Sabates FN: Ophthalmomyiasis intrna Arch ophthalmology 98: 1588-1589; 1986.

[3] Steadly LP, Pererson CA, Ophthalmomyiasis Arch Ophthalmology 1982; 14: 137-9.

[4] Doxanas MT, Watcher JR, Ophthalmomyiasis externa: A case report Md. Med J 41: 989-991, 1992.

[5] Mason GI. Bilateral Ophthalmomyiasis interna. Am J Ophthalmol 1981; 91: 65-70.

[6] Vine AK, Schatz H. Bilateral posterior ophthalmomyiasis. Ann Ophthalmol 1981; 13: 1041-3. 
[7] Jakobs SM, Adelberg DA, Lewis JM, et al. Ophthalmomyiasis interna posterior, report of a case with optic atrophy. Retina 1997; 17: 310-4.

[8] Helmut Beuttmer, MD, Ophthalmomyiasis Interna Arch ophthalmology 2002; 120: 598-1599.

[9] Nicoleyumanets. Internal posterior ophthalmomyiasis. A case report. Retinal physician 2012.
[10] Nilufar. Internal ophthalmimyiasis presenting as endophthalmitis Ophthalmic Surg Lasers Imaging. Nov-Dec 2003; 34 (6): 472-4.

[11] Chiang HH, Sandhu RK, Baynham J, Wilson DJ, A case of ophthalmomyiasis interna in the Pacific Northwest.

[12] Am J Ophthalmol Case Rep. 2017 Feb 3; 6: 11-14. doi: 10.1016/j.ajoc.2017.01.002. eCollection 2017 Jun. PMID: 29260045. 